\title{
Prophylactic ventral cardiac denervation: Does it reduce incidence of atrial fibrillation after coronary artery bypass grafting?
}

\author{
Abbas Salehi Omran, MD, ${ }^{\mathrm{a}}$ Abbasali Karimi, MD, ${ }^{\mathrm{a}}$ Hossein Ahmadi, MD, ${ }^{\mathrm{a}}$ Parin Yazdanifard, MD, \\ Mahmood Sheikh Fahtollahi, PhD, ${ }^{\mathrm{b}}$ and Mokhtar Tazik, MD ${ }^{\mathrm{b}}$
}

Objective: This study assessed the prophylactic effect of ventral cardiac denervation on reducing atrial fibrillation after coronary artery bypass grafting.

\begin{abstract}
Methods: This randomized prospective study recruited 220 adult patients (aged 42-79 years) who were scheduled to undergo coronary artery bypass grafting. Of these patients, 110 underwent ventral cardiac denervation in addition to coronary artery bypass grafting and 110 underwent only coronary artery bypass grafting. The demographic, intraoperative, and postoperative factors comprising atrial fibrillation were compared between the 2 groups. In addition, the predictive factors of atrial fibrillation in all 220 cases were assessed.
\end{abstract}

\begin{abstract}
Results: The mean age and the distribution of gender, body mass index, diabetes mellitus, chronic obstructive pulmonary disease, hypertension, hypercholesterolemia, and left main disease were not significantly different between the 2 groups. Atrial fibrillation incidence was significantly different between the groups $(P=.025)$, with an incidence of $20.9 \%$ in the ventral cardiac denervation group and $10 \%$ in the control group. Atrial fibrillation occurred in 34 of the 220 patients, and ventral cardiac denervation was considered as a variable to evaluate its possible role in the prevention of postoperative atrial fibrillation. Our multivariate analysis showed age $(P=.002$; odds ratio, 1.098; confidence interval, 1.034-1.165) and ventral cardiac denervation $(P=.044$; odds ratio, 2.32; confidence interval, 1022-5.298) as the predictive factors of atrial fibrillation after coronary artery bypass grafting.
\end{abstract}

Conclusions: Given the surprising results of the present study demonstrating that ventral cardiac denervation is a predictive factor of atrial fibrillation after coronary artery bypass grafting, ventral cardiac denervation should not be routinely considered for the prevention of atrial fibrillation after coronary artery bypass grafting. ( $\mathrm{J}$ Thorac Cardiovasc Surg 2010;140:1036-9)

Atrial fibrillation (AF) has long been regarded as the most common complication and supraventricular arrhythmia after open surgeries, particularly coronary artery bypass grafting (CABG). Its incidence in the wake of CABG was reported to be within a wide range of $5 \%$ to $40 \%{ }^{1-5}$ In recent years, several studies have focused on various pharmacologic and operative approaches to prevent $\mathrm{AF}$ after cardiac surgery. Ventral cardiac denervation (VCD) is one of these strategies; however, there is controversy surrounding its effect on reducing AF after cardiac surgery. ${ }^{3,4,6,7}$ In VCD, removal of the nerves around the great vessels at the base of the heart primarily reduces the effect of the autonomic tone on the myocardium. ${ }^{4,7}$ This study evaluated the effectiveness of this technique in reducing the incidence of $\mathrm{AF}$ after CABG in patients at the Tehran Heart Center.

From the Cardiovascular Surgery Department ${ }^{\mathrm{a}}$ and Clinical Research Department, ${ }^{\mathrm{b}}$ Tehran Heart Center, Tehran University of Medical Sciences, Tehran, Iran.

Disclosures: None.

Received for publication July 7, 2009; revisions received Nov 18, 2009; accepted for publication Dec 9, 2009; available ahead of print March 12, 2010.

Address for reprints: Abbas Salehi Omran, MD, Assistant Professor of cardiovascular surgery, Tehran Heart Center, Tehran University of Medical Sciences, North Kargar Street, Tehran, Iran 1411713138 (E-mail: abbasomran2006@yahoo.com).

$0022-5223 / \$ 36.00$

Copyright (c) 2010 by The American Association for Thoracic Surgery doi:10.1016/j.jtcvs.2009.12.024

\section{PATIENTS AND METHODS}

\section{Study Population}

This randomized prospective study, conducted from January 2007 to December 2008, recruited 220 adult patients (age range, 42-79 years) who were scheduled for CABG. The study was approved by the hospital ethics committee, and written inform consent was preoperatively obtained from the patients.

Patients with a history of cardiac surgeries and AF were excluded from the study. A total of 220 patients were randomly divided into 2 groups according to a computer-generated randomization table: A total of 110 patients underwent VCD in addition to CABG (group I), and 110 patients underwent only CABG (control group = group II). All patients were on a beta-blocker regimen preoperatively and postoperatively and underwent on-pump CABG under mild hypothermia with crystalloid cardioplegia. All operations were performed by the same surgeon at the Tehran Heart Center.

The demographic, intraoperative, and postoperative factors comprising AF were compared between the 2 groups. In addition, the predictive factors of AF in all 220 cases were assessed.

\section{Definition of Study Variables}

The preoperative variables comprised gender, history of diabetes, hypertension, hypercholesterolemia, chronic obstructive pulmonary disease, Canadian Cardiovascular Society classification (grades III and IV), latest preoperative potassium $(\mathrm{K}+)$, and left main disease.

Cardiopulmonary bypass (CPB) and crossclamp times and the number of grafts were the intraoperative variables. Postoperative AF, premature atrial contraction, premature ventricular contraction, ventricular tachycardia, ventricular fibrillation, and some major morbidities, including reoperation for 


$$
\begin{aligned}
& \text { Abbreviations and Acronyms } \\
& \begin{aligned}
\text { AF } & =\text { atrial fibrillation } \\
\text { CABG } & =\text { coronary artery bypass grafting } \\
\text { CPB } & =\text { cardiopulmonary bypass } \\
\text { ECG } & =\text { electrocardiography } \\
\text { ICU } & =\text { intensive care unit } \\
\text { VCD } & =\text { ventral cardiac denervation }
\end{aligned}
\end{aligned}
$$

bleeding, transient ischemic attack, stroke, pulmonary emboli, and heart attack, were the postoperative variables assessed.

\section{Definition of Hospital Stay Length}

Number of days a patient stayed at the hospital after surgery. The definitions of all the aforementioned variables are in accordance with our data bank. $^{8}$

\section{Ventricular Cardiac Denervation}

VCD was performed via the same technique described by Melo and colleagues $^{3}$ and Alex and Guvendik. ${ }^{4}$ The nerves around the great vessels were removed at the base of the heart by removing the fat pads. Denervation was commenced from the ascending aorta (supracoronary) by means of removing the alveolar, nerve, and other surrounding tissues using electrocautery and was thereafter extended to the pulmonary artery and superior vena cava (Figure 1). After VCD, all these 110 patients underwent CPB and $\mathrm{CABG}$ in the same manner as the 110 control patients under mild hypothermia with crystalloid cardioplegia.

\section{Electrocardiography}

All patients were closely monitored by continuous electrocardiography (ECG) for at least 72 hours after surgery in the open heart intensive care unit (ICU) and post-ICU before they were transferred to the open heart ward at the discretion of the surgeon and anesthesiologist. In the ward, 12-lead ECG was performed routinely, also taking into account any symptoms and signs such as palpitation. In case of any episode of AF or other arrhythmias, the patients were transferred to the post-ICU, where they were once again kept under continuous ECG monitoring.

\section{Statistical Analysis}

The univariate analysis of the continuous variables was performed with the Student $t$ test, and the categoric variables were compared using the chisquare test and Fisher's exact test, as appropriate. The variables were included in the multivariate logistic regression model if the $P$ value was found to be less than .15 in the univariate analysis. The association of the independent predictors with $\mathrm{AF}$ in the final model was expressed as odds ratio with $95 \%$ confidence intervals. For the statistical analyses, SPSS version 13.0 (SPSS Inc, Chicago, IL) and SAS version 9.1 (SAS Institute Inc, Cary, NC) were used. All $P$ values were 2 -tailed.

\section{RESULTS}

Of the 220 patients who underwent CABG, 110 also underwent VCD (case group) and the remaining 110 were the control group. The mean age and the distribution of gender, body mass index, diabetes mellitus, chronic obstructive pulmonary disease, hypertension, hypercholesterolemia, and left main disease were not significantly different between the 2 groups. Table 1 shows the univariate analysis of the

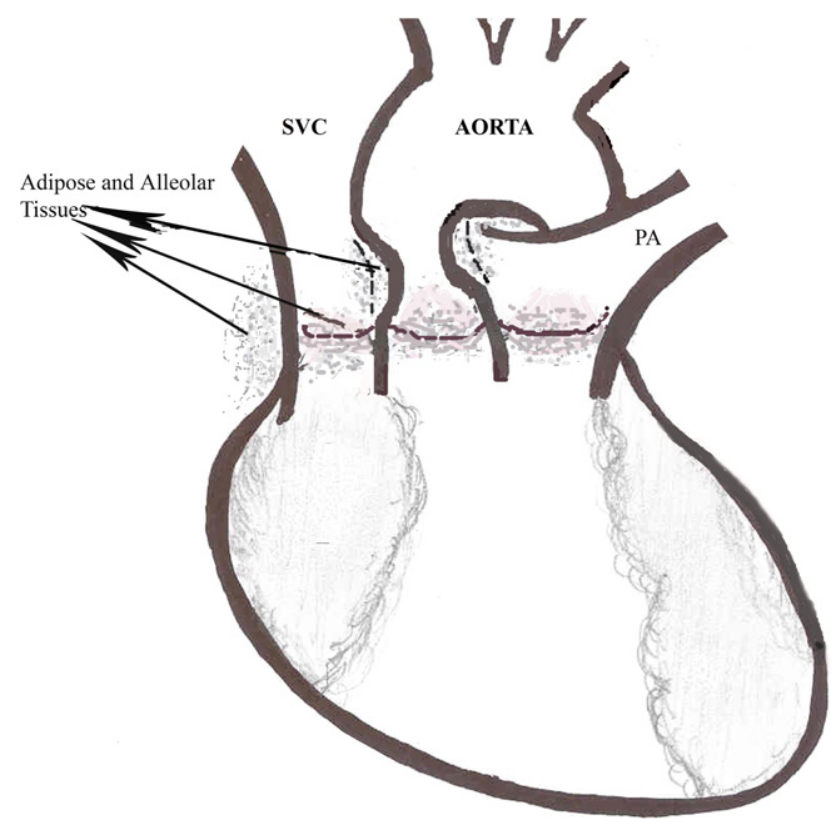

FIGURE 1. Schematic view of VCD with removal of the adipose and alveolar tissues around the outer side of the great vessels of the heart. SVC, Superior vena cava; $P A$, pulmonary artery.

preoperative, intraoperative, and postoperative variables between the groups. AF was significantly different between the groups $(P=.025)$, with an incidence of $20.9 \%$ in the VCD group and $10 \%$ in the control group. The number of AF attacks that occurred during the hospital stay and converted to sinus rhythm with or without treatment was recorded in all the patients. The first attack occurred $2.35 \pm 1.69$ days and $1.71 \pm 1.25$ days after the operation in the VCD and control groups, respectively, which was not significantly different $(P=.370)$. Of the 23 patients with $\mathrm{AF}$ in the VCD group, 11 had 1 episode, 5 had 2 episodes, and 7 had 3 episodes of AF attacks. Of the 11 patients with $\mathrm{AF}$ in the control group, 8 had 1 episode, 2 had 2 episodes, and 1 had 3 episodes of AF attacks. Notably, none of the patients with AF rhythm was discharged until the rhythm had returned to normal sinus rhythm.

AF occurred in 34 of 220 patients, and we considered VCD as a variable to assess its potential role in the prevention of postoperative AF. Our multivariable analysis suggested age and VCD as factors affecting the occurrence of $\mathrm{AF}$ after $\mathrm{CABG}$ in our study population (Tables 2 and 3).

We also recorded the incidences of repeated premature atrial contraction, premature ventricular contraction, ventricular tachycardia, and ventricular fibrillation in the groups (Table 1). The incidences of these arrhythmias were not significantly different between the groups, although the incidence was higher in the VCD group. Permanent pacemaker implantation was not required in either of the groups.

The major morbidity rates, listed in Table 1 , seemed to be relevant to VCD and length of hospital stay. There was only 
TABLE 1. Demographic and perioperative variables between the 2 groups*

\begin{tabular}{|c|c|c|c|}
\hline $\begin{array}{c}\text { Patient } \\
\text { characteristics }\end{array}$ & $\begin{array}{c}\text { VCD group } \\
\text { n (\%) }\end{array}$ & $\begin{array}{c}\text { Control } \\
\text { group n }(\%)\end{array}$ & $P$ value \\
\hline Patient no. $(\mathrm{n}=200)$ & 110 & 110 & \\
\hline Age (y) & $63.47 \pm 7.80$ & $62.18 \pm 7$ & 198 \\
\hline Male & $89(80.9 \%)$ & $88(80 \%)$ & .865 \\
\hline Female & $19(19.1 \%)$ & $22(20 \%)$ & \\
\hline COPD & $7(6.4 \%)$ & $8(7.3 \%)$ & .789 \\
\hline Diabetes mellitus & $34(30.9 \%)$ & $29(26.4 \%)$ & .456 \\
\hline Hypercholesterolemia & $55(50 \%)$ & $55(50 \%)$ & 1 \\
\hline Hypertension & $50(45.5 \%)$ & $60(54.5 \%)$ & .178 \\
\hline CCS grades III and IV & $54(49.1 \%)$ & $45(41.3 \%)$ & .246 \\
\hline $\mathrm{K}^{+}($potassium $)$ & $4.38 \pm 0.37$ & $4.42 \pm 0.44$ & .412 \\
\hline Left main disease & $9(8.9 \%)$ & $7(6.6 \%)$ & .534 \\
\hline BMI & $26.32 \pm 4.15$ & $27.12 \pm 5.02$ & .203 \\
\hline CPB time (min) & $66.62 \pm 13.61$ & $60.91 \pm 16.44$ & .005 \\
\hline Crossclamp time (min) & $38.74 \pm 8.42$ & $36.63 \pm 17.35$ & .253 \\
\hline No. of grafts & $3.86 \pm 0.77$ & $3.27 \pm 0.77$ & $<.001$ \\
\hline LITA as arterial conduit & $110(100 \%)$ & $109(99.1 \%)$ & 1 \\
\hline SVG & $2.84 \pm 0.79$ & $2.27 \pm 0.77$ & $<.001$ \\
\hline $\mathrm{AF}$ & $23(20.9 \%)$ & $11(10 \%)$ & .025 \\
\hline PVC & $16(14.5 \%)$ & $10(9.1 \%)$ & .210 \\
\hline PAC & $14(12.7 \%)$ & $19(17.3 \%)$ & .345 \\
\hline $\mathrm{VT} / \mathrm{VF}$ & $1(0.9 \%)$ & $3(2.7 \%)$ & .372 \\
\hline Reoperation for bleeding & $3(2.7 \%)$ & $3(2.7 \%)$ & 1 \\
\hline TIA/stroke & $1(0.9 \%)$ & $1(0.9 \%)$ & 1 \\
\hline Pulmonary emboli & $2(1.8 \%)$ & 0 & .498 \\
\hline Heart block & 0 & 0 & - \\
\hline Hospital stay & $8.01 \pm 3.92$ & $7.16 \pm 3.20$ & .081 \\
\hline 30-d mortality & 0 & $1(0.9 \%)$ & 1 \\
\hline
\end{tabular}

$V C D$, Ventral cardiac denervation; $C O P D$, chronic obstructive pulmonary disease; $C C S$, Canadian Cardiovascular Society classification; $B M I$, body mass index; $C P B$, cardiopulmonary bypass; LITA, left internal thoracic artery; SVG, saphenous vein grafting; $A F$, atrial fibrillation; $P A C$, premature atrial contraction; $P V C$, premature ventricular contraction; $V T$, ventricular tachycardia; $V F$, ventricular fibrillation; TIA, transient ischemic attack. *Data are presented as mean \pm standard deviation.

1 case of 30-day mortality in the control group, which was the result of ventricular fibrillation and cardiac arrest.

\section{DISCUSSION}

VCD was first described in 1936 by Arnulff ${ }^{9}$ and was used for the prevention of coronary spasm several years later. ${ }^{6}$ Currently, it is deemed as a safe and fast method for reducing the fluctuating autonomic tone and, subsequently, postoperative AF by cutting the autonomic nerves around the great vessels in the base of the heart without prolonging the operation time. ${ }^{3,4}$ However, there is still some controversy in the literature over the efficacy of this method in blunting post-CABG AF. ${ }^{3,4,6}$ In a large nonrandomized population study, Melo and colleagues ${ }^{3}$ reported a significant reduction in the incidence of $\mathrm{AF}$ after $\mathrm{CABG}$ from $27 \%$ in the control group to $7 \%$ in the VCD group. Nonetheless, this sufficient effect of VCD seems to be affected by the telemetry monitoring of only $15 \%$ of the patients during hospitalization and performing the VCD procedure by different
TABLE 2. Univariate analysis of predictive factors of atrial fibrillation after coronary artery bypass grafting*

\begin{tabular}{lccc}
\hline Patient characteristics & AF, n (\%) & No AF, n (\%) & $\boldsymbol{P}$ value \\
\hline Patient no. & $34(15.5 \%)$ & $186(84.5 \%)$ & \\
Age (y) & $66.59 \pm 6.69$ & $62.14 \pm 7.36$ & .001 \\
Male & $25(79.4 \%)$ & $150(80.6 \%)$ & .868 \\
Female & $7(20.6 \%)$ & $36(19.4 \%)$ & \\
COPD & $1(2.9 \%)$ & $14(7.5 \%)$ & .477 \\
Diabetes mellitus & $8(23.5 \%)$ & $55(29.6 \%)$ & .474 \\
Hypercholesterolemia & $16(47.1 \%)$ & $94(50.5 \%)$ & .709 \\
Hypertension & $21(61.8 \%)$ & $89(47.8 \%)$ & .136 \\
CCS grades III and IV & $20(60.6 \%)$ & $79(42.5 \%)$ & .054 \\
K (potassium) & $4.49 \pm 0.42$ & $4.38 \pm 0.40$ & .187 \\
Left main disease & $2(6.5 \%)$ & $14(8 \%)$ & 1 \\
BMI & $27.14 \pm 4.66$ & $26.66 \pm 4.63$ & .588 \\
CPB time (min) & $66.32 \pm 16.31$ & $63.30 \pm 14.94$ & .286 \\
Crossclamp time (min) & $38.26 \pm 9.23$ & $37.58 \pm 14.33$ & .787 \\
No. of grafts & $3.67 \pm 1$ & $3.54 \pm 0.79$ & .411 \\
LITA graft as & $34(100 \%)$ & $185(99.5 \%)$ & 1 \\
$\quad$ & & & \\
arterial conduit & & $2.52 \pm 0.79$ & .338 \\
VCD & $2.67 \pm 1$ & $87(46.8 \%)$ & .025 \\
\hline
\end{tabular}

$A F$, Atrial fibrillation; $C O P D$, chronic obstructive pulmonary disease; $C C S$, Canadian Cardiovascular Society; $B M I$, body mass index; $C P B$, cardiopulmonary bypass; LITA, left internal thoracic artery; $S V G$, saphenous vein graft; $V C D$, ventral cardiac denervation. *Data are presented as $\mathrm{n}(\%)$ for categoric variables and mean \pm standard deviation for numeric variables.

surgeons. ${ }^{3}$ In contrast to Melo and colleagues' study, some recent studies have shown lower or no efficacy of VCD in reducing post-CABG AF. ${ }^{4,6}$ Alex and Guvendik ${ }^{4}$ reported no significant effect of VCD in decreasing the incidence rate of post-CABG AF (29\% in the case group vs $34 \%$ in the control group). In 2004, Cummings and colleagues ${ }^{7}$ suggested that the removal of the adipose tissue during denervation might even increase the incidence of $\mathrm{AF}$ after $\mathrm{CABG}$ (37\% in the case group vs $7 \%$ in the control group). In 2008 , Breda and colleagues ${ }^{6}$ demonstrated the adverse effect of VCD on post-CABG AF $(12 \%$ in the VCD group vs $8 \%$ in the control group). In our study, AF was significantly higher in the VCD group (20.9\% vs $10 \%)$, which is in agreement with recent studies. ${ }^{4,6,7}$ Our finding was confirmed by the multivariate regression analysis for predicting post-CABG AF, which highlighted age and VCD as the predictive factors of postoperative AF, which may be due to such factors as close monitoring of the patients, recording any paroxysmal $\mathrm{AF}$ rhythm, or performing

TABLE 3. Predictors of atrial fibrillation after coronary artery bypass grafting: Results of multivariate analysis

\begin{tabular}{lccc}
\hline $\begin{array}{c}\text { Patient } \\
\text { characteristics }\end{array}$ & $\boldsymbol{P}$ value & Odds ratio & $\begin{array}{c}\mathbf{9 5} \% \text { confidence } \\
\text { interval }\end{array}$ \\
\hline Age & .002 & 1.098 & $1.034-1.165$ \\
VCD & .044 & 2.32 & $1.022-5.298$ \\
\hline
\end{tabular}

$V C D$, Ventral cardiac denervation. Hosmer-Lemeshow goodness-of-fit test; chisquare $=7.5941, d f=8, P=.4741$, area under the receiver operating characteristic curve; $\mathrm{c}=0.74652$. 
procedures by the same surgeon. As Table 1 shows, confounding factors such as demographic variables and length of hospital stay were not significantly different between the groups. CPB time was significantly different between the groups in the univariate analysis and lasted approximately 5 to 7 minutes; thus, CPB time does not seem to be clinically effective in the occurrence of postoperative AF. Furthermore, the multivariate regression analysis did not predict $\mathrm{CPB}$ time as an independent factor for postCABG AF (Table 3).

Some intractable arrhythmias, such as premature atrial contraction, ventricular tachycardia, and ventricular fibrillation, were not significantly different between the groups. On the other hand, the incidence of repeated premature ventricular contraction was more common in the VCD group, although it was not significantly different. AF and premature ventricular contraction might occur after destruction of the nerves and disturbance of the autonomic nervation balance and blood supply to the sinoatrial node, and there is higher rate of eradication of the parasympathetic fibers compared with the sympathetic fibers. Further studies are required to corroborate this.

In the present study, all patients were receiving betablockers as premedication, which was continued postoperatively. Diabetic patients were enrolled in the study, and our analysis showed the same distribution of these patients into the 2 groups with a postoperative AF occurrence of $11.8 \%$ in the diabetic patients of the VCD group (4/34) and $13.8 \%$ in the diabetic patients of the control group. It seems that the bias noted by Alex and Guvendik ${ }^{4}$ regarding the effect of diabetes mellitus and beta-blockers on VCDs did not confound the study.

\section{Study Limitations}

When the patients were transferred from the ICU to the open heart ward (as decided by the surgeon and anesthesiologist) after at least 72 hours of close monitoring by con- tinuous ECG, only 12-lead ECG was provided, which is also routine in case of any symptoms and signs such as palpitation. Afterward, if any of the patients experienced any episode of AF or other arrhythmias, they were transferred to the post-ICU, where continuous ECG was once again provided. Had all the patients been closely monitored at all times, the rate of recorded AF may have increased.

\section{CONCLUSIONS}

In light of these results and the increasing chance of post-VCD adhesion, which renders redo surgery difficult, VCD should not be routinely practiced to prevent postCABG AF until further studies have clarified its effect on postoperative $\mathrm{AF}$.

\section{References}

1. DiDomenico RJ, Massad MG. Pharmacologic strategies for prevention of atrial fibrillation after open heart surgery. Ann Thorac Surg. 2005;79:728-40.

2. Bagshaw SM, Galbraith PD, Mitchell LB, Sauve R, Exner DV, Ghali WA. Prophylactic amiodarone for prevention of atrial fibrillation after cardiac surgery: a metaanalysis. Ann Thorac Surg. 2006;82:1927-37.

3. Melo J, Voigt P, Sonmez B, Ferreira M, Abecasis M, Rebocho M, et al. Ventral cardiac denervation reduces the incidence of atrial fibrillation after coronary artery bypass grafting. J Thorac Cardiovasc Surg. 2004;127:511-6.

4. Alex J, Guvendik L. Evaluation of ventral cardiac denervation as a prophylaxis against atrial fibrillation after coronary artery bypass grafting. Ann Thorac Surg. 2005;79:517-20.

5. Haghjoo M, Saravi M, Hashemi MJ, Hosseini S, Givtaj N, Ghafarinejad MH, et al. Optimal beta-blocker for prevention of atrial fibrillation after on-pump coronary artery bypass graft surgery: carvedilol versus metoprolol. Heart Rhythm. 2007;4: 1170-4.

6. Breda JR, Breda AS, Freitas AC, Meneghini A, Tavares CM, Abreu LC et al. Effect of ventral cardiac denervation in the incidence of atrial fibrillation after coronary artery bypass graft surgery. Rev Bras Cir Cardiovasc. 2008;23:204-8

7. Cummings JE, Gill I, Akhrass R, Dery M, Biblo LA, Quan KJ. Preservation of the anterior fat pad paradoxically decreases the incidence of postoperative atrial fibrillation in humans. J Am Coll Cardiol. 2004;43:994-1000.

8. Karimi A, Ahmadi H, Davoodi S, Movahedi N, Marzban M, Abbasi K, et al Factors affecting postoperative morbidity and mortality in isolated coronary artery bypass graft surgery. Surg Today. 2008;38:890-8.

9. Arnulff G. De la section du plexes pré-aortique: justification et technique. Presse Med. 1939;94:1635-41. 